\title{
ASPECTOS E IMPACTOS AMBIENTAIS DE UM LABORATÓRIO DE BIOLOGIA
}

\author{
J. M. S. MENDONÇA* e R. G. SILVA \\ Instituto Federal de Educação, Ciência e Tecnologia do Rio Grande do Norte (IFRN) \\ jaisa.mendonca@ifrn.edu.br
}

Artigo submetido em setembro/2015 e aceito em dezembro/2015

DOI: $10.15628 /$ holos.2015.2297

\section{RESUMO}

O presente trabalho tem como objetivo avaliar os aspectos e impactos ambientais de um laboratório de Biologia do IFRN Campus Natal Central (CNAT). A pesquisa é do tipo exploratória e descritiva, na qual foram adotados como procedimentos as pesquisas bibliográfica e documental e o estudo caso. Para avaliação de aspectos e impactos do laboratório foi adotado o método de Análise dos Modos e Efeitos das Falhas (FMEA). Como resultados constatou-se que nos doze processos do laboratório há oito tipos de aspectos ambientais que causam cinco tipos de impactos ambientais. $50 \%$ dos aspectos ambientais foram considerados significativos (prioridade I) e os outros como não significativos (prioridade II). Por fim, foram recomendadas ações para todos os aspectos ambientais, com ênfase nos aspectos significativos, com o objetivo de evitá-los ou controlá-los.

PALAVRAS-CHAVE: Aspectos ambientais, impactos ambientais, FMEA, laboratório de biologia.

\section{ASPECTS AND ENVIRONMENTAL IMPACTS OF BIOLOGY LABORATORY}

\begin{abstract}
The present study aims to evaluate the environmental aspects and impacts of a IFRN Biology laboratory of the Campus Natal Central (CNAT). The research is exploratory and descriptive, in which was adopted as proceeding bibliographical and documental research and case study. For evaluation of the laboratory aspects and impacts was adopted Failure Mode and Effects Analysis (FMEA). As a result it was found that on the twelve laboratory
\end{abstract}

processes there are eight types of environmental aspects that cause five types of environmental impacts. $50 \%$ of the environmental aspects were considered significant (priority I) and others as not significant (priority II). Finally, actions were recommended for all environmental aspects, with emphasis on significant aspects, in order to avoid them or control them.

KEYWORDS: Environmental aspects, environmental impacts, FMEA, biology laboratory. 


\section{INTRODUÇÃO}

A preocupação com a gestão ambiental de processos em laboratórios de ensino e pesquisa no Brasil iniciou-se a partir da década de 90 por meio do programa de atuação responsável, o qual estabelece, entre outros procedimentos, a proteção ambiental, saúde e segurança do trabalhador, sendo este programa importante principalmente para as organizações que possuem esses laboratórios, como é o caso de várias instituições de ensino e pesquisa (AFONSO et al., 2003).

A falta de comprometimento da alta administração em adotar ferramentas de gestão ambiental nos laboratórios e a ausência de um órgão fiscalizador, tem promovido à poluição do meio ambiente e as instituições de ensino e pesquisa podem ser penalizadas legalmente e financeiramente pelo mau gerenciamento dos aspectos e impactos ambientais gerados nos processos de um laboratório.

Nesse contexto, a gestão ambiental em instituições de ensino assume um papel relevante, uma vez que essas contribuem de forma significativa para o desenvolvimento da sociedade. A função das instituições de ensino supera a de educar apenas com a transmissão de princípios, mas levar esses princípios à prática. Assim sendo, a elaboração de projetos voltados para a gestão do ambiente e segurança, com o envolvimento da comunidade acadêmica, reveste-se de particular interesse e importância (FONSECA et al., 2005).

O IFRN Campus Natal Central (CNAT), localizado à Av. Senador Salgado Filho, 1559, Tirol, Natal-RN, vem adotando medidas a fim de fomentar a implantação da gestão ambiental neste Campus por meio do Programa Agenda Ambiental Pública (A3P), o qual visa a inserção da variável socioambiental no cotidiano da instituição e na qualidade de vida do ambiente de trabalho (BRASIL, 2013). Ciente da problemática ambiental que envolve os laboratórios, o presente trabalho tem como objetivo avaliar os aspectos e impactos ambientais dos processos realizados no laboratório de Biologia da Diretoria Acadêmica de Ciências (DIAC) do IFRN CNAT, por meio da aplicação do método de Análise dos Modos e Efeitos das Falhas (FMEA).

A escolha desse laboratório, o qual foi criado a pouco mais de 20 anos, se deu por: não apresentar qualquer procedimento que avalie os aspectos e impactos ambientais de suas atividades; ausência de gerenciamento e destinação adequada de resíduos perigosos, e; facilidade de obtenção de dados e conhecimento das atividades do laboratório visto que um dos autores é técnico do laboratório.

Quanto a escolha do método FMEA este se deu pelo fato de ser: um método amplamente utilizado em várias áreas do conhecimento desde 1949; ajuda a identificar de forma qualitativa, pontos em um sistema que tem maior probabilidade de falha que necessitam de uma ação preventiva, para evitar que a falha ocorra; sua aplicação permite identificar pontos em potencial suscetíveis a falha, permitindo elaboração de ações para eliminá-los ou contê-los, e; é de fácil entendimento, adaptação e montagem, sendo este último na forma de uma planilha (SCHMITT, 2013).

\section{ASPECTOS, IMPACTOS AMBIENTAIS E O MÉTODO FMEA}

Aspecto ambiental é "um elemento das atividades, produtos ou serviços de uma organização que pode interagir com o meio ambiente" (ABNT, 2004). Um aspecto ambiental significativo é aquele que tem ou pode ter um impacto significativo, ou seja, importante. $O$ aspecto 
ambiental decorre do consumo (inputs ou entradas) por meio do uso de insumos, como água e energia, matérias-primas, espaço e outros recursos produtivos e do uso do meio ambiente como receptor (outputs ou saídas) de resíduos sólidos, efluentes líquidos, emissões de gases, ruídos, vibrações e radiações, provenientes de atividades ou serviços (BARBIERI, 2007).

A norma ISO 14001:2004 sobre gestão ambiental, elaborada em meados da década de 90, foi a predecessora deste conceito, o qual ainda vem sendo incorporado ao vocabulário ambiental das organizações públicas e privadas. É importante destacar que o aspecto ambiental é um elemento antecessor do impacto ambiental, ou seja, o aspecto é a causa do impacto e este último é o efeito do aspecto. Portanto, a emissão de dióxido de carbono, a geração de resíduos sólidos, por exemplo, são aspectos e não impactos ambientais. Impacto são as alterações, positivas ou negativas, da qualidade ambiental que resultam de aspectos ambientais (SÁNCHEZ, 2006).

O conceito de impacto ambiental também está inserido na legislação brasileira, descrito na Resolução de 23 de Janeiro de 1986 do Conselho Nacional de Meio Ambiente (CONAMA), o qual pode ser definido como qualquer modificação das propriedades físicas, químicas e biológicas do meio ambiente, causada por qualquer forma de matéria ou energia resultante das atividades antrópicas que, direta ou indiretamente, afetam, em suma: a saúde e as atividades sociais e econômicas da população; a biota, as condições estéticas e sanitárias e a qualidade dos recursos do meio ambiente (BRASIL, 1986).

Por outro lado o Failure Mode and Effects Analysis (FMEA) ou Análise dos Modos e Efeitos das Falhas pode ser definido como um método de análise de projetos sejam eles de produtos ou processos, industriais e/ou administrativos, o qual tem como objetivo identificar todos os possíveis modos potenciais de falha e determinar o efeito de cada uma sobre o desempenho do produto ou processo, mediante um raciocínio basicamente dedutivo (HELMAN \& ANDERY, 1995).

O FMEA foi desenvolvido em 1949 por militares americanos, com o objetivo de determinar o efeito da ocorrência de falha em sistemas e em equipamentos e, a partir de 1988 começou a ser adotado como parte dos programas avançados de planejamento da qualidade em projetos e processos em empresas como a Chrysler, Ford e General Motors (MATOS \& MILAN, 2009).

Vandenbrande (1998) foi um dos precursores na adaptação do método FMEA para a avaliação de impactos em Sistemas de Gestão Ambiental (SGA). Segundo ele o método adaptado além de analisar os riscos ambientais de atividades, processos ou produtos, é capaz de priorizar ações para reduzir os impactos negativos. Atualmente, algumas organizações já utilizam o FMEA para iniciar o processo de implantação do SGA, pois ela permite avaliar e identificar falhas, determinando o efeito e identificando ações que possam eliminar ou reduzir a sua ocorrência, ou seja, atuando na redução ou eliminação de aspectos que, por conseguinte, reduzem ou eliminam impactos ambientais (CAMPANI et al., 2006; PESSIN; JÚNIOR \& RIGOTI et al., 2009).

Segundo Zambrano \& Martins (2007) o FMEA, após a fase de identificação das falhas prováveis em projetos ou processo, deve estabelecer as prioridades para o tratamento das falhas e implantação das ações recomendadas. Os resultados das ações recomendadas devem ser analisados para observar se houve diminuição da probabilidade de ocorrência da falha, destacando assim, que a constante aplicação do FMEA resultará na melhoria contínua da organização. 


\section{PROCEDIMENTOS METODOLÓGICOS}

O trabalho em tela trata-se de uma pesquisa exploratória e descritiva (GIL, 2007), na qual, inicialmente, houve uma pesquisa bibliográfica em livros, dissertações, teses e artigos científicos de revistas e congressos; e a pesquisa documental em documentos legais e normas da com o intuito de aprofundar-se teoricamente nos temas discutidos neste trabalho e definir a metodologia a ser utilizada para atingir o objetivo proposto.

Em seguida, foi adotado o estudo de caso com objetivo de alcançar uma observação participante e detalhada, no qual a coleta de dados foi realizada por meio da um checklist (Quadro 6), observação sistemática (GIL, 2007) e anotações dos processos (aulas práticas) do laboratório de Biologia, durante um período de sete meses, compreendido entre junho à dezembro/2013, correspondente a três bimestres letivos completos, no IFRN/CNAT, o que possibilitou conhecer e caracterizar os aspectos ambientais relacionados ao laboratório. Neste período uma limpeza nos armários de reagentes foi realizada no laboratório de biologia, sendo também considerada como um processo.

Para a identificação desses aspectos e dos impactos ambientais foi utilizado o método de Análise dos Modos e Efeitos das Falhas (FMEA) adaptado de Campani et al. (2006), os quais destacam que essa ferramenta é importante em função da priorização que ela possibilita através da aplicação de índices de criticidade, os quais agregam valores para que possam ser avaliados os maiores riscos ambientais associados às facilidades de implementar ações corretivas. A aplicação do FMEA, neste trabalho, seguiu os seguintes passos (CAMPANI et al. ,2006):

1. Definição do ambiente (laboratório de Biologia da DIAC);

2. Identificação dos aspectos e impactos ambientais do ambiente;

3. Identificação das causas dos aspectos/impactos ambientais. Foram identificadas as causas potenciais geradoras de aspectos/impactos ambientais;

4. Identificação dos controles atuais de deteç̧ão das falhas ou causas. Levantamento das formas de controle. Foram analisadas as possibilidades de resposta à implantação das ações;

5. Atribuição dos valores dos índices de criticidade. Foram determinados os três índices de criticidade $(G, O, D)$, os quais serão comentados a seguir;

6. Desenvolvimento dos Planos de Ações (Ação Recomendada), ou seja, proposição de ações de prevenção ou correção para eliminar ou reduzir os aspectos e impactos ambientais.

7. Determinação do Índice de Risco Ambiental (IRA). O índice é resultante da multiplicação dos valores estimados para os quatro índices de criticidade $(G, O, D)$.

Quanto aos valores atribuídos aos índices de criticidade, estes foram classificados numa escala de 0 a 10 para os índices G, O, D, onde o G significa o Índice de Gravidade do Impacto em relação ao meio ambiente e as pessoas envolvidas (Quadro 01); o O significa o Índice de Ocorrência da causa, ou seja, ocorrência da causa potencial (Quadro 02); o D significa o Índice de Detecção do aspecto ambiental baseado na sua respectiva causa potencial (Quadro 03). 
Quadro 01: Diretrizes para classificar o índice de gravidade do impacto (G).

\begin{tabular}{|c|c|}
\hline Escala & Critério \\
\hline 1 & Dificilmente será visível \\
\hline 2 & Muito baixa para ocasionar algum impacto significativo \\
\hline 3 & Baixa, mas poderá ocasionar impacto ao ambiente em longo prazo \\
\hline 4 & Não conformidade com a política ambiental da organização \\
\hline 5 & Não conformidade com os requisitos legais e normativos. Potencial de prejuízo baixo ao meio ambiente \\
\hline 6 & $\begin{array}{l}\text { Não conformidade com os requisitos legais e normativos. Potencial de prejuízo moderado ao meio } \\
\text { ambiente }\end{array}$ \\
\hline 7 & Prejuízo somente à saúde das pessoas diretamente envolvidas com a tarefa \\
\hline 8 & $\begin{array}{l}\text { Significativo prejuízo à saúde das pessoas diretamente envolvidas com a tarefa, com baixo impacto ao } \\
\text { ambiente }\end{array}$ \\
\hline 9 & $\begin{array}{l}\text { Alto prejuízo à saúde das pessoas diretamente envolvidas com a tarefa, com moderado impacto ao } \\
\text { ambiente }\end{array}$ \\
\hline 10 & Alto risco ao ambiente e à saúde das pessoas nos arredores da organização \\
\hline
\end{tabular}

Fonte: Adaptado de Campani et al. (2006); Vandenbrande (1998).

Quadro 02: Diretrizes para classificar o índice de ocorrência da causa (0).

\begin{tabular}{l|l}
\hline Escala & Critério \\
\hline 1 & Improvável: não foi observada ocorrência em período maior que o de referência* \\
2 & Remota: ocorreu uma vez no período, mas é improvável uma nova ocorrência \\
3 & Muito baixo: ocorreu uma vez no período, e pode ocorrer novamente \\
4 & Baixo: ocorreu duas vezes no período de observação \\
5 & Médio baixo: ocorreu três vezes no período de observação \\
6 & Médio: ocorreu quatro vezes no período de observação \\
7 & Médio alto: ocorreu cinco vezes no período de observação \\
8 & Alto: ocorreu seis vezes no período de observação \\
9 & Muito Alto: grande possibilidade de ocorrer cada vez que executada a tarefa. \\
10 & Sempre: ocorre sempre que se executa a tarefa \\
\hline
\end{tabular}

*junho à dezembro de 2013 (6 meses).

Fonte: Adaptado de Campani et al. (2006); Vandenbrande (1998).

Quadro 03: Diretrizes para classificar o índice de detecção (D).

\begin{tabular}{l|l}
\hline Escala & Critério \\
\hline 1 & Detecção rápida e solução rápida. \\
2 & Deteç̧ão rápida e solução a médio prazo. \\
3 & Deteç̧ão a médio prazo e solução rápida. \\
4 & Deteç̧ão rápida e solução a longo prazo. \\
5 & Deteç̧ão a médio prazo e solução a médio prazo. \\
6 & Deteç̧ão a longo prazo e solução rápida. \\
7 & Deteç̧ão a médio prazo e solução a longo prazo. \\
8 & Deteção a longo prazo e solução médio prazo. \\
9 & Detecção a longo prazo e solução longo prazo. \\
10 & Sem detecção e/ou sem solução. \\
\hline
\end{tabular}

Fonte: Adaptado de Campani et al. (2006); Vandenbrande (1998).

Após a atribuição dos valores foi elaborado o FMEA, no qual tem os procedimentos para determinação do IRA. Para tanto, na primeira coluna, descreveu-se o processo, na segunda os aspectos e, na terceira, os impactos ambientais. Na quarta coluna, classificou-se o índice de gravidade do impacto $(G)$ e, na quinta coluna, a causa potencial do aspecto ambiental. Na sexta coluna, classificou-se o índice de ocorrência da causa $(0)$ e na sétima coluna foi descrito (se houve) a forma atual de controle do aspecto ambiental. Na oitava coluna, classificou-se o índice de detecção do aspecto ambiental (D). Na nona coluna, houve a multiplicação dos valores estimados 
dos três índices de criticidade (G, O, D), fornecendo valores de 1 a 1000. Por fim, na décima coluna, foram recomendadas ações para evitar ou mitigar o aspecto ambiental. O quadro 4, abaixo apresenta as diretrizes para determinação de IRA do FMEA.

Quadro 4: Diretrizes para determinação de IRA do FMEA

\begin{tabular}{c|c|c|c|c|c|c|c|c|c}
\hline Processo & $\begin{array}{c}\text { Aspectos } \\
\text { ambientais }\end{array}$ & $\begin{array}{c}\text { Impactos } \\
\text { ambientais }\end{array}$ & $\mathbf{G}$ & $\begin{array}{c}\text { Causa } \\
\text { potencial }\end{array}$ & $\mathbf{O}$ & $\begin{array}{c}\text { Forma atual de } \\
\text { controle }\end{array}$ & D & IRA & Ação recomendada \\
\hline & & & & & & & & & \\
\hline
\end{tabular}

Fonte: Adaptado de Campani et al. (2006).

Depois da determinação dos IRAs foram calculadas as suas médias em cada aspecto ambiental. A determinação da média de IRA foi necessária para apontar um valor médio de IRA para cada aspecto ambiental e, por conseguinte, identificar e selecionar os aspectos ambientais significativos, ou seja, aqueles que apresentaram os maiores valores de IRA médio. Segundo Henkels (2002) o objetivo desta etapa é estabelecer uma ordem de classificação para os aspectos e impactos ambientais identificados e avaliados. A partir dos resultados obtidos através dos critérios ambientais referentes aos aspectos, é possível priorizá-los.

Cabe ressaltar a importância desta etapa visto que a norma ISO 14001/2004, de Sistema de Gestão Ambiental (SGA), determinar que uma organização deve assegurar que os aspectos ambientais significativos sejam levados em consideração no estabelecimento, implementação e manutenção de seu SGA.

Nesse sentido, Henkels (2002) estabelece uma ordem de classificação dividida em quatro níveis de prioridade, mas neste trabalho, para melhor adaptação da metodologia para os dados obtidos, os níveis de prioridades foram reduzidos para dois, conforme demonstra o Quadro 5 abaixo:

Quadro 5: Priorização dos aspectos ambientais

\begin{tabular}{c|c}
\hline Prioridade & Critério \\
\hline I & $\begin{array}{c}\text { 50\% dos aspectos ambientais com os maiores resultados. Caso haja um mesmo aspecto com igual } \\
\text { pontuação, o mesmo deve ser incluído nesta prioridade. Esses são serão considerados os aspectos } \\
\text { ambientais significativos. }\end{array}$ \\
\hline II & $\begin{array}{c}\text { Demais aspectos ambientais, ou seja, aqueles que não se enquadram nos critérios da prioridade I. } \\
\text { Esses serão considerados aspectos ambientais não significativos. }\end{array}$ \\
\hline
\end{tabular}

Fonte: Adaptado de Henkels (2002).

\section{RESULTADOS E DISCUSSÃO}

A listagem dos aspectos de entradas e saídas, de acordo com os processos que ocorrem no laboratório de modo geral, apresentam-se no fluxograma da Figura 1.

As aulas práticas que utilizaram as mesmas metodologias foram divididas em processos para melhor levantar os aspectos e impactos, totalizando 12 processos, sendo eles: limpeza do armário de reagente e retirada de reagentes vencidos e as aulas de tipagem sanguínea, de segurança em laboratório, de visão geral da Biologia, de anatomia do sistema reprodutor, de identificação de substâncias orgânicas, de plâncton marinho, de citologia I, de protozoários, de classificação geral dos vegetais, de osmose e preparação de lâmina e, por fim, de microscopia. 


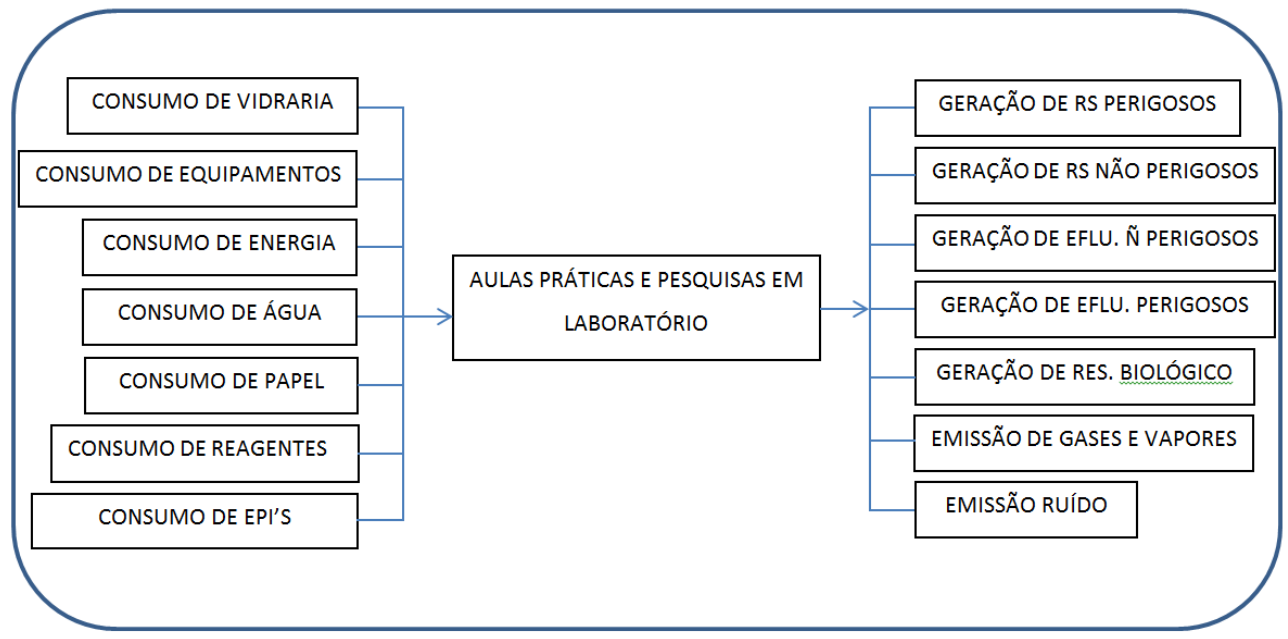

Figura 1: Fluxograma de entradas e saídas (aspectos ambientais) do laboratório de Biologia do IFRN/DIAC/CNAT.

Levando-se em consideração a repetição de alguns impactos ambientais por serem comuns às aulas analisadas, o valor de alguns IRAs se repetiu com frequência, bem como a causa, a forma de controle e a ação recomendada, sendo então, comentado apenas uma vez.

Utilizando o método FMEA nos 12 processos do laboratório de biologia da DIAC/IFRN chegou-se aos resultados apresentados no Quadro 6:

Quadro 6: resultado do checklist do FMEA nos processos do laboratório de biologia da DIAC/IRFN

\begin{tabular}{|c|c|c|c|c|c|c|c|c|}
\hline $\begin{array}{c}\text { Aspecto } \\
\text { ambiental }\end{array}$ & $\begin{array}{l}\text { Impacto } \\
\text { ambiental }\end{array}$ & G & Causa potencial & 0 & $\begin{array}{l}\text { Forma atual de } \\
\text { controle }\end{array}$ & D & IRA & Ação Recomendada \\
\hline \multirow{4}{*}{$\begin{array}{l}\text { Geração } \\
\text { de } \\
\text { resíduos } \\
\text { sólidos } \\
\text { perigosos }\end{array}$} & $\begin{array}{l}\text { Contaminação } \\
\text { do solo }\end{array}$ & 10 & \multirow{2}{*}{$\begin{array}{c}\text { Descarte } \\
\text { inadequado/ } \\
\text { Falta de } \\
\text { conscientização } \\
\text { dos usuários }\end{array}$} & 6 & \multirow{2}{*}{$\begin{array}{l}\text { Armazenamento } \\
\text { por tempos } \\
\text { prolongados/ } \\
\text { Empresa para } \\
\text { coleta e } \\
\text { tratamento }\end{array}$} & 2 & 120 & \multirow{2}{*}{$\begin{array}{l}\text { Auditar a empresa } \\
\text { responsável pela coleta e } \\
\text { tratamento dos resíduos/ } \\
\text { Adquirir recipientes } \\
\text { próprios para } \\
\text { armazenamento }\end{array}$} \\
\hline & $\begin{array}{c}\text { Contaminação } \\
\text { de ambientes } \\
\text { aquáticos }\end{array}$ & 10 & & 6 & & 2 & 120 & \\
\hline & $\begin{array}{l}\text { Danos à saúde e } \\
\text { ao bem-estar de } \\
\text { pessoas internas } \\
\text { e externas à } \\
\text { instituição }\end{array}$ & 10 & $\begin{array}{c}\text { Descarte } \\
\text { inadequado/ } \\
\text { Falta de } \\
\text { conscientização } \\
\text { dos usuários }\end{array}$ & 10 & $\begin{array}{c}\text { Armazenamento } \\
\text { em frascos/ } \\
\text { Utilização de } \\
\text { EPI's }\end{array}$ & 2 & 200 & $\begin{array}{l}\text { Aumentar a frequência na } \\
\text { coleta/ Adquirir } \\
\text { recipientes próprios para } \\
\text { armazenamento/ Treinar } \\
\text { continuamente } \\
\text { servidores e bolsistas }\end{array}$ \\
\hline & Poluição visual & 2 & $\begin{array}{r}\text { Demo } \\
\text { cole } \\
\end{array}$ & 10 & $\begin{array}{r}\text { Cole } \\
\text { em }\end{array}$ & 2 & 40 & $\begin{array}{l}\text { Aumentar a frequência da } \\
\text { coleta }\end{array}$ \\
\hline \multirow{2}{*}{$\begin{array}{l}\text { Geração } \\
\text { de } \\
\text { efluentes } \\
\text { perigosos }\end{array}$} & $\begin{array}{l}\text { Contaminação } \\
\text { do solo }\end{array}$ & 10 & $\begin{array}{c}\text { Descarte } \\
\text { inadequado }\end{array}$ & 9 & \multirow{2}{*}{$\begin{array}{c}\text { Armazenamento } \\
\text { por tempos } \\
\text { prolongados/ } \\
\text { Empresa } \\
\text { contratada para } \\
\text { coleta e } \\
\text { tratamento }\end{array}$} & 4 & 360 & \multirow{2}{*}{$\begin{array}{l}\text { Auditar a empresa } \\
\text { responsável pela coleta e } \\
\text { tratamento dos } \\
\text { resíduos/ Adquirir } \\
\text { recipientes próprios para } \\
\text { armazenamento/ } \\
\text { Construir uma mini } \\
\text { estação de } \\
\text { tratamento/Tratar os } \\
\text { efluentes com fibra de } \\
\text { carca de coco verde }\end{array}$} \\
\hline & $\begin{array}{l}\text { Contaminação } \\
\text { de ambientes } \\
\text { aquáticos }\end{array}$ & 10 & $\begin{array}{l}\text { Falha no sistema } \\
\text { de coleta e/ou } \\
\text { tratamento/ } \\
\text { Falta de } \\
\text { conscientização } \\
\text { dos usuários }\end{array}$ & 9 & & 4 & 360 & \\
\hline
\end{tabular}


Quadro 6: Continuação...

\begin{tabular}{|c|c|c|c|c|c|c|c|c|}
\hline $\begin{array}{c}\text { Aspecto } \\
\text { ambiental }\end{array}$ & $\begin{array}{l}\text { Impacto } \\
\text { ambiental }\end{array}$ & $\mathbf{G}$ & $\begin{array}{c}\text { Causa } \\
\text { potencial }\end{array}$ & 0 & $\begin{array}{c}\text { Forma atual de } \\
\text { controle }\end{array}$ & D & IRA & Ação recomendada \\
\hline $\begin{array}{l}\text { Geração de } \\
\text { efluentes } \\
\text { perigosos }\end{array}$ & $\begin{array}{l}\text { Danos à saúde e ao } \\
\text { bem-estar de } \\
\text { servidores e alunos } \\
\text { e população } \\
\text { externa à } \\
\text { instituição }\end{array}$ & 10 & $\begin{array}{l}\text { Manejo } \\
\text { incorreto/ } \\
\text { Falta de } \\
\text { conscientiza- } \\
\text { ção dos } \\
\text { usuários }\end{array}$ & 10 & $\begin{array}{l}\text { Armazenamento } \\
\text { em frascos e } \\
\text { garrafa pet/ } \\
\text { Utilização de } \\
\text { EPI's }\end{array}$ & 4 & 400 & $\begin{array}{c}\text { Aumentar a frequência na } \\
\text { coleta/ Adquirir recipientes } \\
\text { próprios para } \\
\text { armazenamento/ Treinar } \\
\text { continuamente servidores e } \\
\text { bolsistas/ Instalar sistema de } \\
\text { exaustão }\end{array}$ \\
\hline \multirow{2}{*}{$\begin{array}{l}\text { Emissão de } \\
\text { gases e } \\
\text { vapores }\end{array}$} & \multirow{2}{*}{$\begin{array}{l}\text { Danos à saúde e ao } \\
\text { bem-estar de } \\
\text { servidores e alunos }\end{array}$} & \multirow[t]{2}{*}{7} & $\begin{array}{l}\text { Armazena- } \\
\text { mento } \\
\text { incorreto de } \\
\text { reagentes }\end{array}$ & 10 & $\begin{array}{c}\text { Armazenamento } \\
\text { em armários } \\
\text { dentro do } \\
\text { laboratório } \\
\end{array}$ & 2 & 140 & $\begin{array}{c}\text { Construir uma "casa de } \\
\text { reagentes" / Instalar sistema } \\
\text { de exaustão }\end{array}$ \\
\hline & & & $\begin{array}{l}\text { Coleção de } \\
\text { animais em } \\
\text { formaldeído }\end{array}$ & 10 & $\begin{array}{l}\text { Frascos comuns } \\
\text { e sem vedação }\end{array}$ & 4 & 280 & $\begin{array}{c}\text { Vedar os frascos/ Substituir o } \\
\text { formaldeído por outra solução } \\
\text { menos tóxica }\end{array}$ \\
\hline \multirow{3}{*}{$\begin{array}{l}\text { Consumo de } \\
\text { energia }\end{array}$} & \multirow{3}{*}{$\begin{array}{l}\text { Uso/esgotamento } \\
\text { de recursos } \\
\text { naturais }\end{array}$} & \multirow{3}{*}{4} & $\begin{array}{l}\text { Falta de } \\
\text { conscientiza- } \\
\text { ção dos } \\
\text { usuários }\end{array}$ & 4 & Não há controle & 1 & 16 & $\begin{array}{l}\text { Manter equipamentos ligados } \\
\text { apenas quando necessário/ } \\
\text { Instalar placas de aviso/ } \\
\text { Proferir palestras educativas }\end{array}$ \\
\hline & & & $\begin{array}{l}\text { Utilização } \\
\text { inadequada } \\
\text { de } \\
\text { equipamen- } \\
\text { tos }\end{array}$ & 4 & Não há controle & 2 & 32 & $\begin{array}{l}\text { Treinar continuamente os } \\
\text { servidores e bolsistas }\end{array}$ \\
\hline & & & $\begin{array}{l}\text { Falta de } \\
\text { manutenção }\end{array}$ & 8 & Não há controle & 2 & 64 & $\begin{array}{c}\text { Contratar empresas } \\
\text { responsáveis pela manutenção } \\
\text { dos equipamentos/ Aquisição } \\
\text { de equipamentos novos }\end{array}$ \\
\hline \multirow{3}{*}{$\begin{array}{l}\text { Riscos à } \\
\text { saúde } \\
\text { devido às } \\
\text { condições } \\
\text { do ambiente }\end{array}$} & \multirow{3}{*}{$\begin{array}{l}\text { Danos à saúde e ao } \\
\text { bem-estar de } \\
\text { servidores e alunos }\end{array}$} & \multirow[b]{3}{*}{7} & $\begin{array}{l}\text { Ventilação } \\
\text { inadequada }\end{array}$ & 10 & $\begin{array}{c}\text { Abertura das } \\
\text { janelas }\end{array}$ & 2 & 140 & Instalar sistema de exaustão \\
\hline & & & $\begin{array}{l}\text { Falha } \\
\text { ergonômica }\end{array}$ & 10 & Não há controle & 2 & 140 & $\begin{array}{l}\text { Utilizar bancos com altura } \\
\text { regulável }\end{array}$ \\
\hline & & & $\begin{array}{c}\text { Falta de } \\
\text { limpeza do } \\
\text { ar- } \\
\text { condicionado }\end{array}$ & 10 & $\begin{array}{l}\text { Limpeza com } \\
\text { pouca } \\
\text { frequência por } \\
\text { empresa } \\
\text { terceirizada } \\
\end{array}$ & 1 & 70 & $\begin{array}{c}\text { Aumentar a frequência de } \\
\text { Limpeza dos ar- } \\
\text { condicionados }\end{array}$ \\
\hline \multirow[b]{2}{*}{$\begin{array}{l}\text { Emissão } \\
\text { ruídos }\end{array}$} & \multirow{2}{*}{$\begin{array}{l}\text { Danos à saúde e } \\
\text { ao bem-estar de } \\
\text { servidores e } \\
\text { alunos }\end{array}$} & \multirow[b]{2}{*}{7} & $\begin{array}{l}\text { Excesso de } \\
\text { alunos no } \\
\text { laboratório }\end{array}$ & 8 & $\begin{array}{l}\text { Divisão das } \\
\text { turmas }\end{array}$ & 1 & 56 & $\begin{array}{l}\text { Conscientizar os professores } \\
\text { e alunos }\end{array}$ \\
\hline & & & $\begin{array}{c}\text { Falta de } \\
\text { manutenção } \\
\text { dos } \\
\text { equipamento } \\
\text { s } \\
\end{array}$ & 10 & Não há controle & 2 & 140 & $\begin{array}{l}\text { Contratar empresas } \\
\text { responsáveis pela } \\
\text { manutenção dos } \\
\text { equipamentos/ Aquisição de } \\
\text { equipamentos novos }\end{array}$ \\
\hline \multirow{2}{*}{$\begin{array}{l}\text { Consumo } \\
\text { de água }\end{array}$} & \multirow{2}{*}{$\begin{array}{l}\text { Uso/Esgotamento } \\
\text { dos recursos } \\
\text { naturais }\end{array}$} & \multirow[b]{2}{*}{4} & $\begin{array}{c}\text { Falta de } \\
\text { manutenção/ } \\
\text { Vazamentos }\end{array}$ & 8 & Não há controle & 2 & 64 & $\begin{array}{l}\text { Solicitar manutenção ao } \\
\text { setor competente }\end{array}$ \\
\hline & & & $\begin{array}{l}\text { Falta de } \\
\text { conscientiza- } \\
\text { ção dos } \\
\text { usuários }\end{array}$ & 4 & Não há controle & 1 & 16 & Proferir palestras educativas \\
\hline
\end{tabular}


Quadro 6: Continuação...

\begin{tabular}{|c|c|c|c|c|c|c|c|c|}
\hline $\begin{array}{c}\text { Aspecto } \\
\text { ambiental }\end{array}$ & $\begin{array}{l}\text { Impacto } \\
\text { ambiental }\end{array}$ & G & $\begin{array}{c}\text { Causa } \\
\text { potencial }\end{array}$ & 0 & $\begin{array}{c}\text { Forma atual de } \\
\text { controle }\end{array}$ & D & IRA & Ação Recomendada \\
\hline \multirow{2}{*}{$\begin{array}{l}\text { Geração de } \\
\text { resíduos } \\
\text { sólidos não } \\
\text { perigosos }\end{array}$} & \multirow[b]{2}{*}{ Poluição do solo } & \multirow[b]{2}{*}{4} & $\begin{array}{c}\text { Consumo } \\
\text { exagerado de } \\
\text { papel }\end{array}$ & 8 & Não há controle & 1 & 32 & $\begin{array}{c}\text { Melhorar a formatação dos } \\
\text { roteiros/ Imprimir apenas o } \\
\text { necessário }\end{array}$ \\
\hline & & & $\begin{array}{l}\text { Falta de } \\
\text { conscientiza- } \\
\text { ção dos } \\
\text { usuários }\end{array}$ & 8 & Não há controle & 1 & 32 & $\begin{array}{c}\text { Proferir palestras } \\
\text { educativas }\end{array}$ \\
\hline
\end{tabular}

Com base nos resultados do FMEA, a Figura 2 abaixo apresenta os aspectos ambientais com suas respectivas médias de IRA classificando como significativos, ou seja, aqueles que representam $50 \%$ dos aspectos com os maiores resultados (prioridade I) e os que foram classificados como aspectos não significativos (prioridade II):

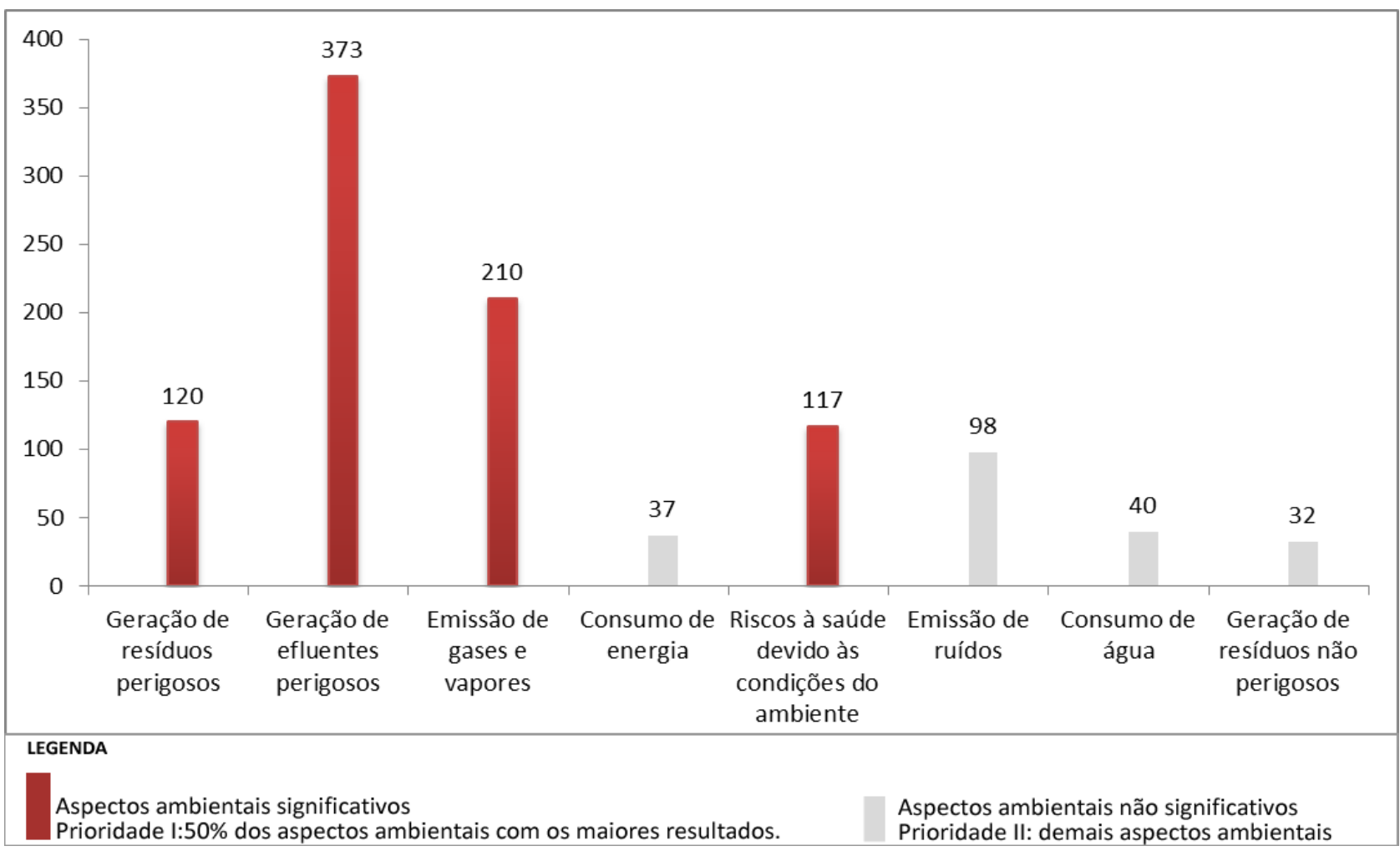

Figura 2: Classificação dos aspectos ambientais do laboratório conforme sua significância.

No que concerne aos aspectos ambientais "geração de resíduos perigosos" e "geração de efluentes perigosos" ressalta-se que apesar de já haver uma empresa contratada para a coleta desses resíduos e efluentes, a frequência com que acontece essa coleta é insuficiente, ocorrendo apenas uma vez no início de cada semestre letivo, ocasionando acumulação de reagentes e soluções vencidos conforme constata-se na Figura 3 abaixo: 


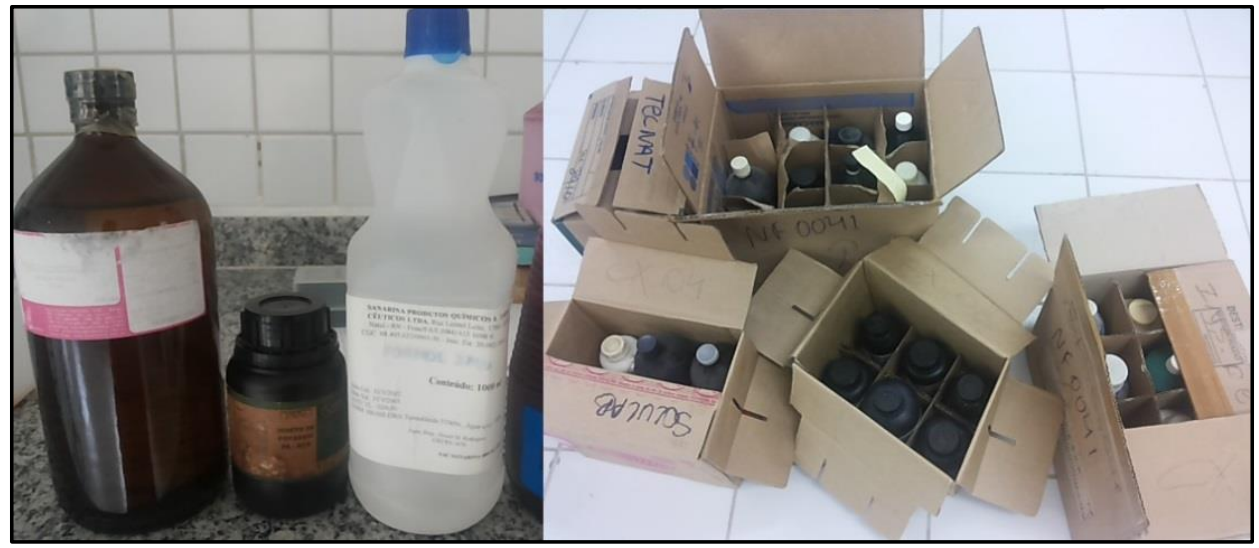

Figura 3: Reagentes e soluções vencidos, aguardando coleta pela empresa responsável. Fonte: Mendonça e Silva (2013).

Com relação ao descarte inadequado foi verificado que ainda são lançados nos ralos das pias resíduos como Formol (10\%), Ácido Clorídrico (10\%) e Lugol (4\%) utilizado nas aulas práticas, devido à ausência de recipientes próprios para armazenamento e posterior descarte. É importante destacar que esses resíduos e efluentes se armazenados ou destinados de forma inadequada em ambientes tanto terrestres quanto aquáticos causam graves impactos ambientais e se tornam uma ameaça à saúde pública, já que diversas enfermidades podem ser transmitidas por veiculação hídrica e pelo acúmulo de lixo (BLOOR \& BANKS, 2006).

No período de realização desta pesquisa, entre Junho e Dezembro de 2013, foram realizadas um total de 33 aulas práticas no laboratório de Biologia, ou seja, pelo menos 5 aulas por mês, e estima-se que foram produzidos 41,555 litros de resíduos líquidos considerados perigosos, bem como resíduos sólidos não pesados conforme apresenta-se no Quadro 7, abaixo:

Quadro 7: Quantidades de resíduos gerados durante as atividades em laboratório no período da pesquisa.

\begin{tabular}{ll}
\hline \multicolumn{1}{c}{ Resíduos } & \multicolumn{1}{c}{ Quantidade } \\
\hline Lancetas & $\sim 260$ unid \\
Algodão & $\sim 260$ unid \\
Lâminas & $\sim 260$ unid \\
Luvas & $\sim 300$ unid \\
HCl a 10\% & $\sim 4$ Litros \\
HCL P.A. & $\sim 2$ Litros \\
Detergente líquido & $\sim 2$ Litros \\
Formol a 10\% & $\sim 21$ Litros \\
Formol a 37\% & $\sim 3$ Litros \\
Formol P.A. & $\sim 4$ Litros \\
Lugol & $\sim 1$ Litro \\
Solução de azul de metileno a 5\% & $\sim 320 \mathrm{ml}$ \\
Óleo de imersão (microscopia) & $\sim 5 \mathrm{ml}$ \\
Álcool Etílico & $\sim 3$ Litros \\
lodeto de Potássio & $\sim 30 \mathrm{~g}$ \\
Peróxido de Hidrogênio & $\sim 700 \mathrm{ml}$ \\
Reativo de Benedict & $\sim 500 \mathrm{ml}$ \\
\hline
\end{tabular}

Fonte: Mendonça e Silva (2013).

As ações recomendadas para controlar esses aspectos e impactos ambientais foram propostas no Quadro 6. Destaca-se, no caso da geração de efluentes perigosos, a sugestão para construção de uma mini Estação de Tratamento de Efluentes (ETE) para tratar os efluentes 
gerados. A ETE pode ter um custo elevado, mas certamente traria um beneficio significativo visto que atenderia outros laboratórios do IFRN CNAT.

Em contraponto, uma alternativa que pode ser mais viável para o tratamento desses efluentes seria a utilização da fibra da casca do coco verde. Silva et al. (2013) apontam que o pó de fibra da casca verde do coco é um adsorvente eficaz e tem um elevado potencial de adsorção no tratamento de efluentes contendo Ferro e Alumínio. Já Souza et al. (2007, p. 1157) afirmam que "o tratamento básico dado ao pó da casca de coco verde com $\mathrm{NaOH} 0,1 \mathrm{~mol} \mathrm{~L}^{-1} / 3 \mathrm{~h}$ promoveu um aumento na capacidade de adsorção dos metais tóxicos $\mathrm{Pb}^{+2}, \mathrm{Ni}^{+2}, \mathrm{Cd}^{+2}, \mathrm{Zn}^{+2}$ e $\mathrm{Cu}^{+2}$ em solução aquosa sintética multielementar". Azevedo (2008), por sua vez, pontua que a fibra da casca de coco verde foi eficiente na remoção da matéria orgânica. Portanto, os trabalhos citados apontam que essa técnica é viável, o que pode servir como referência para servidores e alunos do IFRN Campus Natal Central desenvolverem pesquisas que resultem na implantação de tal técnica no laboratório.

Ressalta-se ainda na questão do descarte de resíduos que nas aulas de "tipagem sanguínea", as luvas e os materiais perfurocortantes utilizados foram descartados em embalagem descarpack (Figura 4), restando as lâminas contaminadas, as quais foram submetidas ao ácido clorídrico em molho por $24 \mathrm{~h}$ e posteriormente lavadas com sabão. Foi recomendado a aquisição de autoclave para melhor esterilização das lâminas, porém a mesma chegou ao laboratório pouco antes do período desta pesquisa ser concluída, quando já haviam ocorrido as aulas de tipagem.

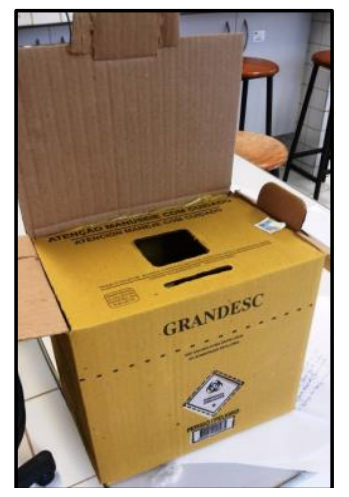

Figura 4: Caixa para descarte de material perfurocortante.

Fonte: Mendonça e Silva (2013).

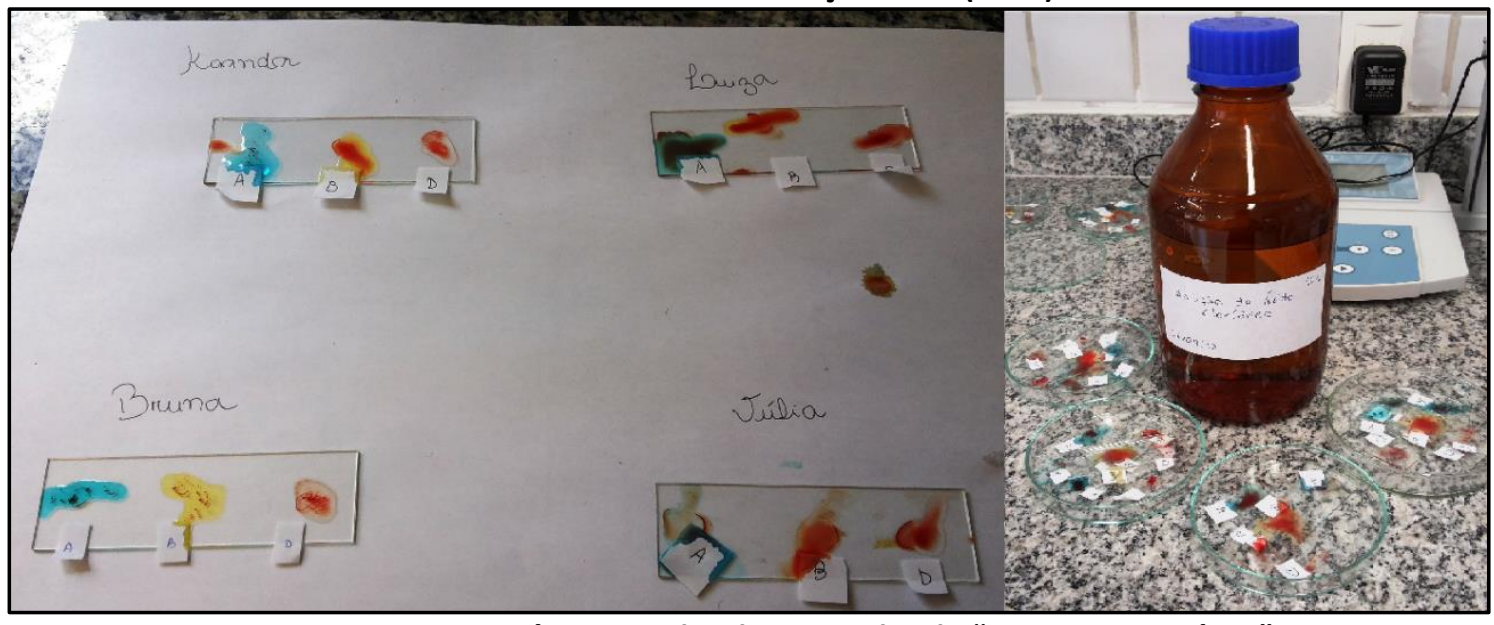

Figura 4: Lâminas utilizadas nas aulas de "tipagem sanguínea".

Fonte: Mendonça e Silva (2013) 
Em relação a outro aspecto ambiental considerado significativo, a "emissão de gases e vapores", esse foi causado pelo armazenamento incorreto dos reagentes e, principalmente, pela coleção de animais em solução de formaldeído, comumente conhecido como formol, em frascos que não estão corretamente vedados, conforme descrito no FMEA, Quadro 06.

O formaldeído, conforme destacam Viegas \& Prista (2009), utilizado como fixador e conservante do material biológico e devido o seu caráter cancerígeno, agravado por picos na concentração durante o período de exposição, o uso do formol merecia uma intervenção rápida para prevenir os potenciais efeitos para a saúde dos trabalhadores expostos em laboratórios. Veronez et al. (2010) pontuam outros efeitos que essa exposição pode causar como irritação às membranas mucosas dos olhos, do nariz, da cavidade nasal, da faringe, da laringe, além de cefaleias, sonolência, náusea e irritação cutânea. Corroborando com isso, Machado \& Mól (2008), recomendam, quando possível, evitar a obtenção e o uso de substâncias de elevada toxicidade como, por exemplo, o formaldeído que, a propósito, não pode ser lançado na rede de esgoto.

Nesse sentido, foi recomendada a construção de uma "casa de reagentes" com sistema exaustor para o armazenamento dos reagentes. Já no caso das coleções de animais em formol as recomendações são: vedar os frascos ou substituir essa solução por outra menos tóxica, o que seria mais recomendado.

Cury, Censoni \& Ambrósio (2013) estudaram quatro técnicas para fixação e conservação de material biológico: a glicerinação, a criodesidratação, a injeção de látex, e a injeção de vinil, as quais eles afirmam que além de representar maior ética com o meio ambiente, a maioria é de baixo custo, apresentam grande período de conservação, fornecem melhor didática de estudo para professores e alunos porque mostram estruturas externas e internas dos animais, não sendo necessária a inserção de inúmeras substâncias e materiais para uso de diferentes técnicas que fariam a mesma função. Portanto, tal estudo pode servir como referência para servidores e alunos do IFRN Campus Natal Central desenvolverem pesquisas que resultem na implantação de pelo menos uma dessas técnicas no laboratório de biologia estudado.

Quanto ao último aspecto ambiental significativo "risco à saúde devido às condições do ambiente", esse é causado pela ventilação inadequada, falha ergonômica e falta de limpeza de arcondicionado.

Para a ventilação inadequada a ação recomendada foi a instalação de sistema exaustor. Já no caso da falha ergonômica recomendou-se a aquisição de bancos com altura regulável e, por fim, no caso da falta de limpeza de ar-condicionado recomendou-se aumentar a frequência de limpeza dos ar-condicionados. É possível observar que as ações recomendadas pata evitar ou mitigar tais problemas não são difíceis de serem implantadas e possuem um custo não muito alto, porém atingem todas as pessoas envolvidas no processo.

Senna et al. (2013), que também utilizou o método FMEA numa unidade de uma Instituição Federal Multicampi de Ensino Superior constatou que as principais causas potenciais dos impactos ambientais foram: falta de iluminação, falta de ventilação, depósito inadequado do material e mau dimensionamento do sistema elétrico. Enquanto no presente trabalho, além da falta de ventilação e armazenamento incorreto, destacam-se o descarte inadequado, falha no sistema de coleta, falta de conscientização dos usuários e falta de manutenção de maneira geral.

Em períodos de preparação das aulas práticas foi possível observar que a água deionizada é priorizada em relação a destilada pelo técnico de laboratório, devido ao consumo menor de água residual na produção da água deionizada. Em nenhum dos processos utilizados é feito o 
reaproveitamento da água residual. Outro problema com o consumo de água são as torneiras velhas, que apresentam vazamento quando não forçadas.

Júnior, Bacarji \& Bonnati (2011), ao listar os aspectos e impactos ambientais do Instituto Federal de Educação, Ciência e Tecnologia de Mato Grosso (IFMG), Campus Cuiabá-Bela Vista, também constatou o descarte de resíduos laboratoriais em pias e a necessidade de ações que mudem os hábitos dos frequentadores com relação ao consumo de água, papel e energia.

\section{CONCLUSÕES}

O método FMEA se mostrou satisfatório para o levantamento e avaliação dos aspectos e impactos ambientais do Laboratório de Biologia da DIAC do IFRN CNAT, auxiliando na identificação, quantificação e qualificação dos aspectos ambientais. Cabe destacar que o método possibilitou também um alto nível de detalhamento dos processos, listando seus aspectos e impactos, suas potenciais causas, ocorrência, forma de controle atual, e permitiu sugerir ações para prevenir ou minimizar os aspectos e impactos ambientais associados.

Cabe pontuar que no caso da priorização de aspectos ambientais o método FMEA apresentou limitações, visto que não há qualquer procedimento quantitativo ou qualitativo que determine o que é significativo, ou seja, o que será priorizado. Para tanto, recorreu-se a metodologia de priorização de aspectos ambientais adotado por Henkels (2002), que neste trabalho, foi adaptada.

A grande quantidade de pessoas envolvidas nos processos, dentre servidores e alunos, também foi outra limitação deste trabalho porque dificultou a coleta das informações durante as aulas, o que impossibilitou, inclusive, expandir a pesquisa para outros laboratórios da instituição.

Quanto a importância dos resultados o trabalhou constatou que a geração de resíduos perigosos, a geração de efluentes perigosos, a emissão de gases e vapores e os riscos à saúde devido às condições do ambiente são os principais aspectos ambientais do laboratório de biologia estudado, uma vez que apresentaram $50 \%$ dos aspectos ambientais com os maiores resultados de média de IRA, o que determinou a significância desses aspectos ambientais sendo classificados como aspectos de prioridade I. Por sua vez, tais aspectos ambientais significativos geraram impactos significativos como os danos à saúde e ao bem-estar dos servidores e alunos envolvidos nos processos do laboratório, o que é preocupante.

A estrutura antiga do laboratório estudado, o qual foi adaptado de uma sala de aula, exigiu reformas para atender as normas de segurança, bem como instalação de equipamentos voltados para a saúde e bem-estar das pessoas, o que ainda tem sido feito de forma lenta devido a burocracia envolvida em órgãos públicos. Certamente, esses fatores contribuíram para alguns resultados negativos no FMEA.

Quanto aos aspectos ambientais do laboratório classificados como não significativos, a saber: consumo de energia, consumo de água, emissão de ruídos e geração de resíduos não perigosos, foram recomendadas também ações para evitar ou mitigar tais aspectos, conforme apresentado no Quadro 6. O fato de serem classificados como não significativos e, portanto, neste trabalho, classificados como prioridade II, apenas os qualificam como menos importantes, o que não impedem de serem controlados.

Sob o ponto de vista do IFRN CNAT, este trabalho pode ser analisado, melhorado e aplicado nos demais laboratórios do IFRN CNAT dando subsídio a A3P da instituição por meio do Projeto 
Campus Verde, o qual tem como objetivo principal implantar a gestão ambiental em cada campus do IFRN de forma sistêmica. Nesse contexto, converge com as considerações de Pessin et al. (2009), os quais afirmam que para o processo de implantação de um Sistema de Gestão Ambiental (SGA) é primordial a sistematização e a hierarquização dos aspectos e impactos ambientais, devendo ser uma das primeiras medidas para a implantação de um SGA, pois assim é possível: o conhecimento das atividades analisadas, dos aspectos ambientais produzidos por estas, dos possíveis impactos decorrentes e das pessoas e partes envolvidas nos processos.

\section{REFERÊNCIAS}

1. AFONSO, J.C. et al. Gerenciamento de resíduos laboratoriais: recuperação de elementos e preparo para descarte final. Química Nova, São Paulo, v. 26, p.602-611, 2003.

2. ASSOCIAÇÃO BRASILEIRA DE NORMAS TÉCNICAS. NBR ISO 14001: Sistemas de gestão ambiental: requisitos com orientações para uso. Rio de Janeiro: ABNT, 2004, 27 p.

3. AZEVEDO, B. de S. M. Utilização da fibra da casca de coco verde como suporte para a formação de biofilme visando o tratamento de efluentes. 2008. 121f. Dissertação (Mestrado em Tecnologia de Processos Químicos e Bioquímicos) - Escola de Química da UniversidadeFederal do Rio de Janeiro. Disponível em: <http://tpqb.eq.ufrj.br/download/fibra-da-casca-de-cocoverde-para-biofilme-visando-o-tratamento-de-efluentes.pdf > Acesso em: 01 de abr. 2015.

4. BARBIERI, J. C. Gestão ambiental empresarial: conceitos, modelos e instrumentos. São Paulo: Saraiva, 2007.

5. BRASIL. Ministério do Meio Ambiente. Termo de adesão A3P. 2013 Disponível em: < http://portal.ifrn.edu.br/servidores/campus-verde/proadscn0111082013091109> Acesso em: 02 de fev. 2015.

6. ___ Conselho Nacional do Meio Ambiente (CONAMA). Dispõe sobre critérios básicos e diretrizes gerais para o Relatório de Impacto Ambiental (RIMA). Resolução n. 001, de 23 de janeiro de 1986. Diário Oficial da União de 17 de Fevereiro de 1986.

7. BLOOR, M.C. \& BANKS, C.J. Acute and sub-lethal toxicity of landfill leachate towards two aquatic macro-invertebrates: demonstrating the remediation potential of aerobic digestion. Hydrobiologia, Londres, 556: 387-397, 2006.

8. CAMPANI, D.B et al. Implementação do Sistema de Gestão Ambiental no prédio da engenharia mecânica - UFRGS. XXX Congresso Interamericano de Ingeniería Sanitaria y Ambiental. Punta del Este/Uruguay. 2006. Disponível em:< http://www.ufrgs.br/sga/SGA/educacao-ambiental1/links/trabalhos/8\%20implantacao_sistema_gestao.pdf> Acesso em: 15 de jan. 2014.

9. CURY, F. S.; CENSONI, J. B. J.; AMBRÓSIO, C. E. Técnicas anatômicas no ensino da prática de anatomia animal. Pesquisa Veterinária Brasileira. v. 33, n.5, p. 688-696, 2013.

10. FONSECA, A. et al. Gestão do ambiente e da segurança em laboratório de ensino. Revista da Faculdade de Ciência e Tecnologia. UFP. p. 216 à 223. 2005. Acesso em: 21/08/2013. Visualizado em: bdigital.ufp.pt/bitstream/10284/580/2/214-223FCT2005-13.pdf

11. HELMAN, H.; ANDERY, P. R. P. Análise de falhas (aplicação dos métodos de FMEA e FTA). Belo Horizonte: Fundação Christiano Ottoni, 1995.

12. JÚNIOR, E.J.C.; BACARJI, A.G.; BONATTI, J.; Levantamento de aspectos e impactos ambientais do Instituto Federal de Educação, Ciência e Tecnologia de Mato Grosso, Campus Cuiabá-Bela 
Vista. II Congresso Brasileiro de Gestão Ambiental. 2011.

13. MACHADO, P.F.L., MÓL, G.S. Resíduos e rejeitos de aulas experimentais: o que fazer? Química Nova na Escola, São Paulo, n. 29, p. 38-41, 2008.

14. MATOS, R. S. B. de; MILAN M.; Aplicação sistêmica do modo de análise de falhas e efeitos (fmea) para o desenvolvimento de indicadores de desempenho de empresas de pequeno porte. Revista Árvore, Viçosa, v.33, n.5, p.-977-985, 2009.

15. MENDONÇA, J. M. S.; SILVA, R. G.. Fotografias. Laboratório de Biologia do Instituto Federal de Educação, Ciência e Tecnologia do Rio Grande do Norte (IFRN). Natal, RN. 2013.

16. PESSIN, N.; JÚNIOR, R. S.; RIGOTI, M. R. Utilização de Metodologia FMEA para a identificação dos aspectos e impactos ambientais em laboratórios de ensaios mecânicos e máquinas operatrizes - Estudo de caso. 25 Congresso Brasileiro de Engenharia Sanitária e Ambiental. ABES. Recife-PE. 2009.

17. ROSS, C. et al. Aplicação da ferramenta FMEA: estudo de caso em uma empresa do setor de transporte de passageiros. Tecno-Lógica, Santa Cruz do Sul, v. 11, n. 1 e 2, p. 29-32, 2007.

18. SÁNCHEZ, L. E. Avaliação de impacto ambiental: conceitos e métodos. São Paulo: oficina de textos, 2006.

19. SENNA, A.J.T. et al. Em busca de uma Universidade mais sustentável: Identificação e análise dos aspectos ambientais de uma unidade de uma Instituição Federal Multicampi de Ensino Superior. IV Congresso Brasileiro de Gestão Ambiental. Salvador/BA. 2013.

20. SILVA, et al. Caracterização físico-química da fibra de coco verde para a adsorção de metais pesadosem efluente de indústria de tintas. ENGEVISTA, Rio de Janeiro, v. 15, n. 1. p. 43-50, 2013

21. SCHMITT, J. C.; Método de análise de falha utilizando a integração das ferramentas DMAIC, RCA, FTA e FMEA. 2013. 98 f. Dissertação (Mestrado em Engenharia de Produção) - Faculdade de Engenharia, Arquitetura e Urbanismo, da Universidade Metodista de Piracicaba, Piracicaba, 2013. Disponível em: < https://www.unimep.br/phpg/bibdig/pdfs/docs/17092013_144838_joseschimitt.pdf> Acesso em: 15 de fev. 2015.

22. SOUZA, F. W. et al. Uso da casca de coco verde como adsorbente na remoção de metais tóxicos. Química Nova, São Paulo, Vol. 30, No. 5, 1153-1157, 2007.

23. VANDENBRANDE, W. W. How to use FMEA to reduce the size of your quality toolbox. Quality Progress. v.31, n.11, p. 97-100, 1998.

24. VERONEZ, D. A. da L. et al. Potencial de risco para a saúde ocupacional de docents, pesquisadores e técnicos de anatomia expostos ao formaldeído. InterfacEHS, São Paulo, v. 5, n.2, p. 63-76, 2010.

25. VIEGAS, S.; PRISTA, J. Estudo da exposição ocupacional a formaldeído num laboratório de anatomia patológica : relevância da aplicação de uma metodologia (PID) de monitorização ambiental. Revista Saúde e Trabalho, Lisboa, v7, 31-45, 2009

26. VIEIRA, I.C.M. Melhoria da Qualidade no Projeto e na Fabricação - estudo de caso de uma empresa construtora de autocarros. 2012. 40f.Dissertação (Mestrado Integrado em Engenharia Metalúrgica e de Materiais) - Faculdade de Engenharia da Universidade do Porto. 
Portugal. 2012. Disponível em: <http://repositorioaberto.up.pt/bitstream/10216/65021/2/950167.pdf> Acesso em: 10 de jan. 2014.

27. ZAMBRANO, T. F.; MARTINS, M. F.; Utilização do método FMEA para avaliação do risco ambiental. Gestão e Produção, São Carlos, v. 14, n. 2, p. 295-309, 2007. 